\title{
Reações de defesas químicas e estruturais de Lonchocarpus muehlbergianus Hassl. (Fabaceae) à ação do galhador Euphalerus ostreoides Crawf. (Hemiptera: Psyllidae)
}

\author{
DÊNIS COELHO DE OLIVEIRA ${ }^{1}$ JACIARA DE CÁSSIA SOUZA CHRISTIANO ${ }^{1}$, \\ GERALDO LUIZ GONÇALVES SOARES ${ }^{2}$ e ROSY MARY DOS SANTOS ISAIAS ${ }^{1,3}$
}

(recebido: 1 de setembro de 2005; aceito: 16 de novembro de 2006)

\begin{abstract}
Structural and chemical defensive reactions of Lonchocarpus muehlbergianus Hassl. (Fabaceae) to Euphalerus ostreoides Crawf. (Hemiptera: Psyllidae) galling stimuli). Galls are plant structure induced in response to stimuli of a gall-inducing organism. Euphalerus ostreoides induces galls on the adaxial surface of leaflets directly on secondary veins of Lonchocarpus muehlbergianus. Anatomical analyses were performed to compare healthy leaflets, immature and mature gall tissues. Histochemical tests for detection of phenolic derivatives, flavonoids, lignins, lipids and starch were performed to check the chemical impact of gall-inducing action. The lost of sinuosity of epidermal cells, the neoformation of trichomes, of conducting cells, and fibres were the most conspicuous plant responses features to gall induction. Mesophyll hiperplasia with maintenance of tissue stratification, and accumulation of lipids, starch, flavones, flavonols and flavanones in gall tissues were observed. Nevertheless, the formation of oxonium salts by the reaction with sulfuric acid only in gall tissues was a remarkable feature. The results suggested that $L$. muehlbergianus was submitted to a high oxidative stress induced by the action of E. ostreoides. It was possible to conclude that the structural and chemical alterations observed were considered as plant defensive reactions against herbivory and adaptive mechanisms that favor the galling insect establishment within plant tissues
\end{abstract}

Key words - anatomy, Euphalerus, histochemistry, Lonchocarpus, plant gall

RESUMO - (Reações de defesas químicas e estruturais de Lonchocarpus muehlbergianus Hassl. (Fabaceae) à ação do galhador Euphalerus ostreoides Crawf. (Hemiptera: Psyllidae)). Galhas são estruturas vegetais induzidas em resposta ao ataque de organismos indutores. Euphalerus ostreoides (Psyllidae) induz galhas sobre a face adaxial de folíolos nas nervuras de segunda ordem de Lonchocarpus muehlbergianus (Fabaceae). Seções anatômicas foram realizadas e comparados os tecidos de folíolos sadios com os de galhas imaturas e maduras. Testes histoquímicos para detecção de derivados fenólicos, flavonóides, ligninas, lipídios e amido foram realizados para avaliar o impacto químico causado pelo galhador. Em termos estruturais, a perda de sinuosidade das células epidérmicas, a neoformação de tricomas, de células condutoras e de fibras foram os caracteres mais conspícuos observados em decorrência da indução das galhas. Destaca-se a hiperplasia e hipetrofia do mesofilo com manutenção da estratificação, a produção de gotículas lipídicas e amido, flavonas, flavonóis e flavanonas nos tecidos das galhas. Contudo, a formação de cristais de oxônio pela adição de ácido sulfúrico somente nos tecidos das galhas foi uma característica marcante. Os resultados sugerem que L. muehlbergianus está submetida a alto estresse oxidativo induzido pela ação do E. ostreoides. Conclui-se que as alterações são consideradas reações de defesa da planta contra herbivoria e mecanismos de adaptação que em conjunto favorecem o estabelecimento do galhador nos tecidos vegetais.

Palavras-chave - anatomia, Euphalerus, galha, histoquímica, Lonchocarpus

\section{Introdução}

Células, tecidos e órgãos vegetais estão sujeitos a uma série de fatores, principalmente patológicos, que provocam mudanças no seu desenvolvimento e

\footnotetext{
1. Universidade Federal de Minas Gerais, Instituto de Ciências Biológicas, Departamento de Botânica, Av. Antônio Carlos 6627, Campus Pampulha, 31270-901 Belo Horizonte, MG, Brasil.

2. Universidade Federal do Rio Grande do Sul, Instituto de Biociências, Departamento de Botânica, Av. Bento Gonçalves 9500, Campus do Vale, 91501-970 Porto Alegre, RS, Brasil.

3. Autor para correspondência: rosy@icb.ufmg.br
}

diferenciação (Rohfritsch \& Shorthouse 1982). Algumas das mais complexas formas de desenvolvimento atípico são conhecidas como galhas, estruturas que se originam através de hipertrofia e hiperplasia de tecidos, inibição do desenvolvimento ou modificação citológica em resposta ao ataque de organismos indutores que podem ser vírus, bactérias, fungos, nematódios, ácaros ou insetos (Mani 1964).

Folíolos de Lonchocarpus muehlbergianus Hassl. (Fabaceae) apresentam galhas induzidas pela ação de Euphalerus ostreoides Crawf. (Hemiptera, Psyllidae) na face adaxial de folíolos sobre as nervuras de segunda ordem. As galhas são de formato bivalvar, uniloculares, com uma ninfa por loja (Ferreira et al. 1990). 
O gênero Euphalerus apresenta ampla distribuição geográfica, sendo encontrado em quase todos os continentes, exceto o australiano. E. ostreoides possui duas ou três gerações anuais em seu ciclo de vida (Ferreira et al. 1990) e apresenta grande especificidade ao seu hospedeiro, L. muehlbergianus. A diferenciação do tecido vegetal para formar a galha pode envolver, entre outros, estímulos mecânicos e químicos fornecidos pelo inseto, tais como: mastigação do tecido vegetal, fluidos injetados durante a oviposição, secreções salivares, excretas e hormônios produzidos (Hori 1992).

A ação de herbívoros galhadores pode resultar em profundas alterações estruturais nos tecidos vegetais das plantas hospedeiras. Estas alterações são acompanhadas por modificações bioquímicas, principalmente notadas em relação a metabólitos primários e secundários específicos (Hartley 1998). No primeiro grupo, merecem destaque substâncias com função nutricional, tais como carboidratos e lipídios. Dentre os metabólitos secundários, os derivados fenólicos são freqüentemente citados como substâncias sinalizadoras no processo cecidogênico (Hartley 1999, Soares et al. 2000). Substâncias fenólicas têm grande potencial antioxidante, característica esta que é intensificada paralelamente à produção de espécies reativas de oxigênio (Rao et al. 1996, Queiroz et al. 1998). Muitos destes metabólitos são formados a partir de precursores de um grupo reduzido de metabólitos primários (Castro et al. 2004). Atualmente, compreende-se que estas substâncias são o resultado da especialização celular e que suas manifestações durante certas fases do desenvolvimento vegetal se devem à expressão diferencial dos genes (Gottlieb et al. 1996).

Tanto alterações estruturais quanto químicas têm grande influência na manutenção do ciclo de vida dos galhadores, o qual se passa parcial ou totalmente dentro dos tecidos vegetais, sendo o galhador responsável pela formação, desenvolvimento e manutenção das galhas. Essas são estruturas originadas pelo crescimento atípico do hospedeiro, regulado pela ação do indutor o qual obtém abrigo e nutrição (Isaias 1998).

Este trabalho teve por objetivo estudar o impacto estrutural e químico da ação de Euphalerus ostreoides durante o desenvolvimento da galha de Lonchocarpus muehlbergianus.

\section{Material e métodos}

Folíolos sadios e com galhas em diferentes estádios de desenvolvimento foram coletados de indivíduos de Lonchocarpus muehlbergianus Hassl. utilizados na arborização do Campus da Pampulha da Universidade Federal de Minas Gerais, em Belo Horizonte, MG. Uma exsicata desse material encontra-se depositada no Herbário BHCB sob o número 23110.

Para estudos estruturais foram preparadas lâminas histológicas. Amostras de material sadio e galhado foram fixadas em FAA preparado com etanol $50 \%$ por 48 horas (Johansen 1940), desidratadas em série butílica e infiltradas em Paraplast ${ }^{\circledR}$ (Kraus \& Arduin 1997). O material foi secionado em micrótomo rotatório (8-12 $\mu \mathrm{m}$ de espessura) e corado com solução aquosa de azul de astra $0,5 \%$ e safranina $0,5 \%$ (Bukatsch 1972). Para obtenção de epidermes isoladas, as amostras foram submetidas à técnica de dissociação, utilizando mistura de Jeffrey (ácido crômico 10\% e ácido nítrico 10\%) (Johansen 1940) e coradas com solução aquosa de azul de astra 0,5\% e safranina 0,5\% (Bukatsch 1972).

Para a análise da densidade dos tricomas foram utilizados 10 folíolos sadios e 10 galhas maduras, dos quais foram obtidos fragmentos de $1 \mathrm{~cm}^{2}$ de epidermes isoladas. De 10 fragmentos de cada material, escolhidos aleatoriamente, foram contados os tricomas em 6 campos de $1 \mathrm{~mm}^{2}$ com auxílio de câmara clara acoplada a microscópio de luz. Os dados foram submetidos ao teste ANOVA, seguidos pelo teste de Tukey (5\%).

Para detectar substâncias do metabolismo primário, lipídios e amido, seções de material recém-coletado foram submetidas diretamente às reações com vermelho $\mathrm{B}$ de Sudan (C.I. 26050) em etanol $70^{\circ} \mathrm{GL}$ (Brundett et al. 1991) e reagente de Lugol (Johansen 1940), respectivamente.

Para detecção de derivados fenólicos, as amostras foram fixadas em sulfato ferroso $2 \%$ em formalina (Johansen 1940). A presença de flavonóides mono ou poliméricos (proantocianidinas) foi testada em cortes histológicos de material recém coletado fixados em cafeína/benzoato de sódio $1 \%$ em butanol $90 \%$, e posteriormente transferidos para solução etanólica de $p$-dimetilaminocinamaldeído por 2 horas (Feucht et al. 1986). Derivados flavonoídicos foram testados pela reação com ácido sulfúrico (Zuanazzi 2000). Para a detecção de ligninas foi utilizada solução acidificada de floroglucinol (Johansen 1940).

Testes-controle foram realizados em material recémcoletado, seccionado em micrótomo de mesa, os quais também foram analisados como cortes-branco. Derivados fenólicos e flavonoídicos foram extraídos com reagente de Stockwell (Johansen 1940) por 24 horas e lipídios com clorofórmio:metanol (2:1) v/v (Moore et al. 1991).

As fotomicrografias foram obtidas a partir de lâminas montadas em gelatina glicerinada de Kaiser ou glicerina 50\% (Kraus \& Arduin 1997) em fotomicroscópio de luz.

Para os estudos em Microscopia Eletrônica de Varredura (MEV), amostras de galhas foram fixadas em glutaraldeído $5 \%$ em tampão fosfato $0,1 \mathrm{M}(\mathrm{pH} 7,2)$ por 48 horas a $4{ }^{\circ} \mathrm{C}$ (Bronner 1975). A desidratação foi feita em série etanólica (Johansen 1940) seguida de ponto crítico com gás carbônico e metalização em ouro (O`Brien \& McCully 1981). 


\section{Resultados e Discussão}

As galhas foliolares de Lonchocarpus muehlbergianus Hassl. são formadas ao longo das nervuras de segunda ordem, apresentando-se aleatoriamente dispostas nos folíolos; projetam-se para a face adaxial e assumem formato bivalvar (figuras 1-3). Pela face abaxial, percebe-se o intumescimento formado pelas projeções (figura 4). As alterações teciduais são marcantes nos três sistemas de tecidos, quando comparadas ao folíolo sadio, destacando-se a intensa esclerificação (figura 5).

O sistema de revestimento dos folíolos sadios de L. muehlbergianus apresenta epiderme uniestratificada com células de paredes anticlinais diversamente sinuosas (figuras 6-7). Na face abaxial, são observados tricomas tectores unicelulares, tricomas glandulares sobre as nervuras e estômatos paracíticos (figura 7).

Após a formação da galha, as células epidérmicas perdem a sinuosidade das paredes anticlinais (figuras 8, 12). Na epiderme da face adaxial externa e na interna à loja, há sinais de hiperplasia (figura 8), a epiderme na face abaxial da galha apresenta hiperplasia e hipertrofia celular. A perda de sinuosidade das paredes das células epidérmicas parece ser uma alteração relativamente comum nos processos cecidogênicos, tendo sido descrita anteriormente para galhas em uma espécie de Urtica (Meyer \& Maresquelle 1983) e em diferentes espécies de Machaerium (Isaias 1998). A hipertrofia celular e a hiperplasia tecidual também são reações comuns à diferentes galhas (Kraus et al. 1996, Isaias 1998, Souza et al. 2000).

Tricomas glandulares foram observados sobre as nervuras das galhas na face interna da loja (figura 10). Há neoformação de tricomas tectores no revestimento externo da galha (figuras 8,13 ), aumento da densidade no revestimento interno a loja (tabela 1) e no ápice das valvas (figuras 9, 11). Os tricomas influenciam na manutenção da temperatura e umidade na superfície da folha sadia (Press 1999, Fahn 1990, Woodman \& Fernandes 1991, Gutschick 1999). A neoformação de tricomas na borda das valvas e no revestimento interno da galha pode favorecer a manutenção da temperatura e umidade, fatores fundamentais para o estabelecimento e desenvolvimento do galhador, além de oferecer proteção mecânica contra $\mathrm{o}$ ataque de predadores e cecidófagos como apontado por Woodman \& Fernandes (1991).

Ocasionalmente, estômatos anômalos são formados no revestimento abaxial da galha e no revestimento interno à loja (figura 12). A formação de estômatos anômalos na face externa das galhas já foi descrita anteriormente para galhas de Ficus microcarpa L.f. induzidas por Gynaikothrips ficorum Marchal (Souza et al. 2000). A ocorrência de má formação estomática tanto nos folíolos sadios quanto nas galhas pode estar relacionada a uma característica genética desta espécie vegetal, capaz de variar com as condições ambientais nas quais os indivíduos coletados ocorrem, e possivelmente devido a mudanças no padrão de expansão das células epidérmicas (Glover 2000).

O sistema fundamental do folíolo sadio é constituído por duas a três camadas de células de parênquima paliçádico e duas a três de parênquima lacunoso. Entre o parênquima paliçádico e lacunoso nota-se a presença de um estrato de parênquima paravenal (figura 14).

$\mathrm{Na}$ galha, o sistema fundamental mostra-se formado por parênquima clorofiliano que se desenvolveu pela hipertrofia dos parênquimas paliçádico, lacunoso e paravenal. Durante o desenvolvimento da galha até sua maturação, é possível observar diferenças estruturais e de conteúdo nas células do parênquima da galha, mantendo uma nítida estratificação (figuras 16-18). O parênquima paliçádico origina o parênquima das paredes laterais da galha, o lacunoso origina o parênquima da base da galha e o parênquima paravenal dá origem ao parênquima da região mediana da galha.

A hipertrofia das células parenquimáticas pode estar relacionada à armazenagem de água e balanço hídrico, e acúmulo de substâncias fenólicas. A formação de esclereídes e fibras nas paredes internas da galha conferem sustentação mecânica e proteção contra inimigos naturais do galhador (Kraus 1997). De acordo com Isaias (1998), galhas em diferentes espécies de Machaerium (Fabaceae) apresentaram tendência à homogeneização do parênquima paliçádico e lacunoso, além da esclerificação de algumas destas células em maior ou menor grau e em diferentes posições da galha. Em galhas de L. muehlbergianus, além da estratificação do parênquima como resultado da ontogenia e de conteúdo celular distinto, há formação de uma capa de esclereídes que se desenvolve gradualmente ao longo dos estádios de maturação e se localiza ao redor dos feixes das paredes da galha.

O sistema vascular do folíolo sadio é constituído da nervura de primeira ordem da qual partem perpendicularmente nervuras de segunda ordem. Estas são formadas por feixe vascular colateral, com porção floemática bem desenvolvida e nítida atividade cambial. Fibras perivasculares com lignificação conspícua estão presentes nos folíolos maduros (figura 15). 
Na galha, há hiperplasia do xilema e do floema com neoformação de células condutoras (figura 19). O sistema vascular da galha se dispõe em feixes paralelos nas valvas. Destaca-se uma acentuada atividade cambial das nervuras de segunda ordem parasitadas, principalmente em relação à formação de floema (figuras 16, 20). Euphalerus ostreoides Crawf. possui aparelho bucal sugador, deste modo o maior desenvolvimento do tecido vascular pode ser um fator facilitador pelo aumento da diferenciação de possíveis sítios de alimentação.

Em folíolos sadios, a deposição de lignina se restringe às fibras perivasculares (figura 15). Na galha, há uma intensa lignificação principalmente nas células
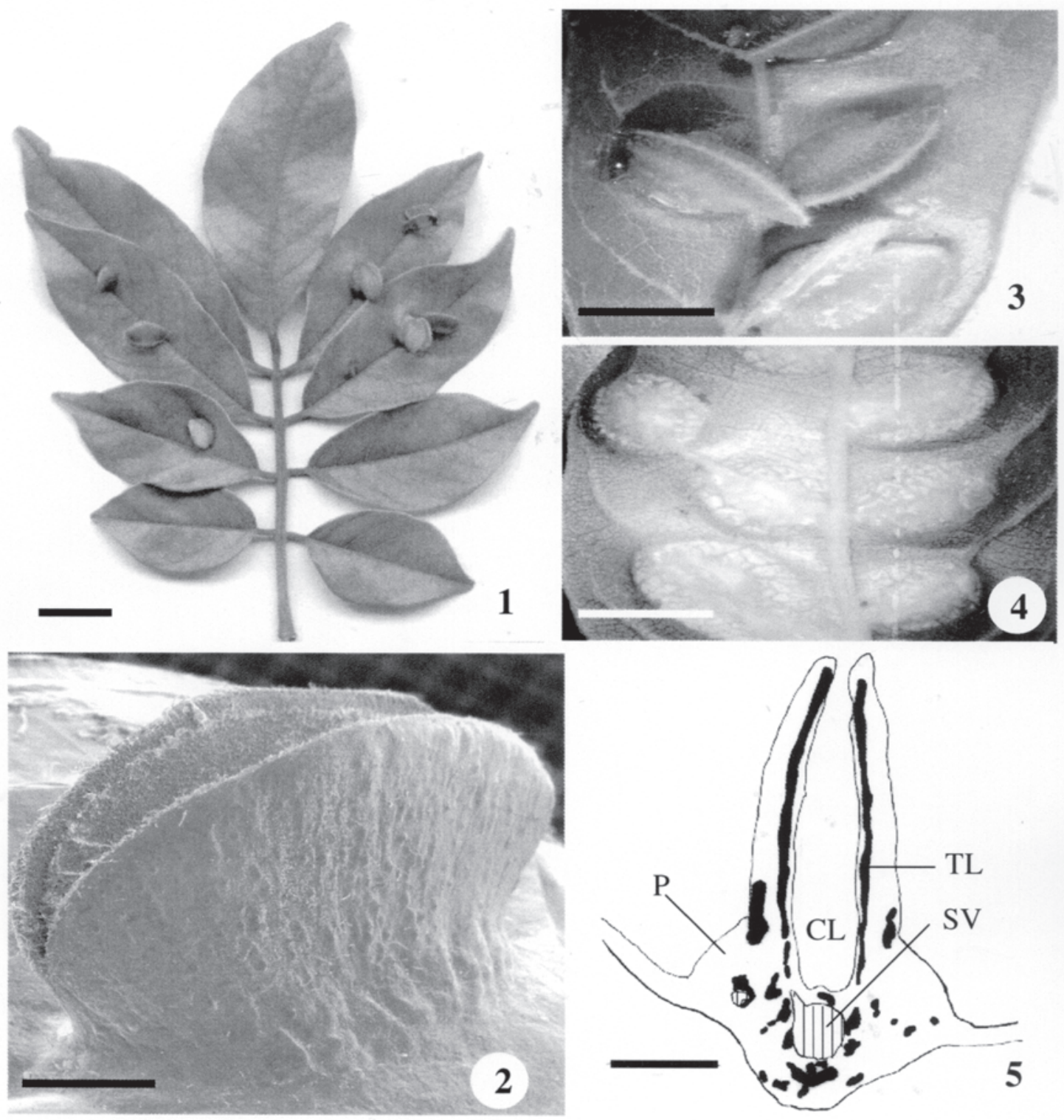

Figuras 1-4. Morfologia externa de Lonchocarpus muehlbergianus Hassl. 1. Folha com folíolos sadios e galhados. 2. Aspecto bivalvar da galha em MEV. 3. Detalhe de galhas vistas pela face adaxial do folíolo. 4. Detalhe de galhas vistas pela face abaxial do folíolo. 5. Diagrama da seção transversal da galha evidenciando disposição dos tecidos. (CL = câmara larval (loja); $\mathrm{P}=$ parênquima; $\mathrm{SV}=$ sistema vascular; $\mathrm{TL}=$ tecido lignificado). Barras $=10 \mathrm{~mm}(1), 5 \mathrm{~mm}(3-4), 1 \mathrm{~mm}(2,5)$.

Figures 1-4. External morphology of Lonchocarpus muehlbergianus Hassl. 1. Leaf with healthy and galled leaflets. 2. Bivalve aspect of the gall in SEM. 3. Detail of galls seen by the adaxial surface of a leaflet. 4. Detail of galls on the abaxial surface of the leaflet. 5. Diagram of the transverse section of a gall showing tissue arrangement. $(\mathrm{CL}=$ larval chamber; $\mathrm{P}=$ parenchyma; $\mathrm{SV}=$ vascular system; $\mathrm{TL}=$ lignified tissue $).$ Bars $=10 \mathrm{~mm}(1), 5 \mathrm{~mm}(3-4), 1 \mathrm{~mm}(2,5)$. 


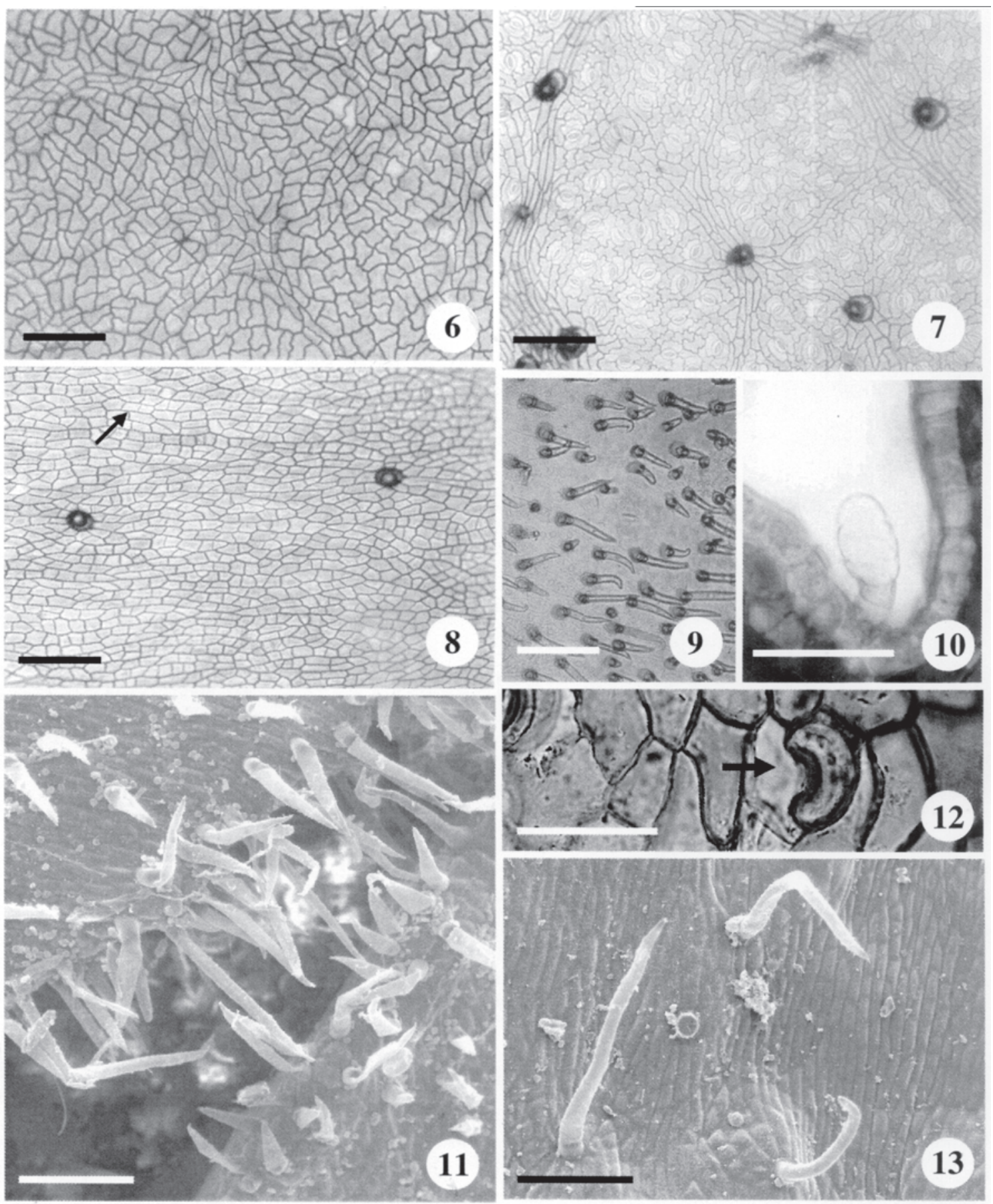

Figuras 6-13. Fotomicrografias de folíolos sadios e galhas de Lonchocarpus muehlbergianus Hassl. 6-7. Epiderme do folíolo sadio, face adaxial (6) e face abaxial (7). 8-13. Epiderme da galha, face adaxial externa (8), face interna da loja (9), detalhe de tricoma glandular sobre a nervura de segunda ordem na face interna da galha (10), detalhe da abertura da galha em MEV (11), epiderme adaxial evidenciando estômato anômalo (seta) (12). 13. Epiderme abaxial da galha em MEV. Barras $=100 \mu \mathrm{m}(6-9,11$, 13), $50 \mu \mathrm{m}(10,12)$.

Figures 6-13. Photomicrographs of healthy leaflets and galls of Lonchocarpus muehlbergianus Hassl. 6-7. Epidermis of healthy leaflet,adaxial surface (6) and abaxial surface (7). 8-13. Gall epidermis, epidermis of the external adaxial surface (8), epidermis of the internal surface of the chamber (9), detail of a glandular trichome on a second order vein in the internal surface of the gall (10), detail of gall aperture in SEM (11), adaxial gall epidermis showing anomalous stomata (arrow) (12). 13. Abaxial gall epidermis in SEM. Bars $=100 \mu \mathrm{m}(6-9,11,13), 50 \mu \mathrm{m}(10,12)$. 
Tabela 1. Densidade de tricomas no tecido de revestimento de folíolos sadios e galhas de Lonchocarpus muehlbergianus Hassl. induzidas por Euphalerus ostreoides Crawf. Médias seguidas da mesma letra não diferem entre si pelo teste de Tukey $(P<0,05)$. $(S=$ desvio padrão $)$.

Table 1. Density of trichomes in dermal tissue of healthy leaflets and galls of Lonchocarpus muehlbergianus Hassl. induced by Euphalerus ostreoides Crawf. Means followed by the same letter are not significantly different based on the Tukey test $(P<0.05)$. ( $S=$ standard deviation).

\begin{tabular}{lc}
\hline Localização & $\begin{array}{c}\text { Tricomas } \mathrm{mm}^{-2} \\
(\text { média } \pm S)\end{array}$ \\
\hline Face externa da galha & $3 \pm 2^{\mathrm{a}}$ \\
Face interna da galha & $207 \pm 70^{\mathrm{b}}$ \\
Face adaxial do folíolo sadio & $2 \pm 0^{\mathrm{a}}$ \\
Face abaxial do folíolo sadio & $2 \pm 0^{\mathrm{a}}$ \\
\hline
\end{tabular}

da base e ao redor dos feixes da parede da galha (figuras 21-22). A lignificação das paredes internas e das células da base das galhas bem como o aumento quantitativo de esclereídes e de fibras nas galhas maduras ocorre, muito provavelmente, devido à reação da planta contra radicais livres de oxigênio (Gottlieb et al. 1996). Deste modo, a maior lignificação observada nas galhas maduras, em relação às imaturas, sugere $o$ aumento do estresse oxidativo (Harkin \& Obst 1973, Lange et al. 1995, Low \& Merida 1996), induzido pela ação do E. ostreoides. Trabalhos recentes têm demonstrado que as secreções orais de alguns herbívoros contêm glicose-oxidase (Felton \& Eichenseer 1999), que pode aumentar a produção de peróxido de hidrogênio $\left(\mathrm{H}_{2} \mathrm{O}_{2}\right)$ no sítio da herbivoria e estimular a formação de outras espécies reativas de oxigênio.

A formação de fibras que circundam a estrutura interna da galha é responsável pela sustentação e proteção mecânica contra cecidófagos. Segundo Stone (2003), a diversificação das estruturas internas da galha tem provavelmente levado a um aumento do suprimento nutritivo enquanto a diversificação externa das estruturas está provavelmente relacionada à defesa. A diversificação das estruturas internas da galha no sistema L. muehlbergianus - E. ostreoides está relacionada tanto à nutrição do galhador quanto à sua proteção, isto se sustenta pela presença de feixes de fibras que circundam as paredes da galha.

Além das mudanças estruturais, as presumíveis alterações no metabolismo primário das galhas foram observadas indiretamente e podem estar relacionadas principalmente à armazenagem de nutrientes para o crescimento e manutenção da galha. Gotículas lipídicas foram detectadas no parênquima de folíolos sadios e nas cavidades secretoras presentes no mesofilo de L. muehlbergianus (figura 23) e já descritas por Teixeira et al. (2000). Esta forma de reserva foi observada no parênquima ao redor da câmara ninfal em galhas imaturas e maduras em quantidades relativamente similares (figura 24). Lipídios representam substâncias químicas de reserva de energia e possíveis precursores de componentes importantes para o metabolismo da planta (Buchnan et al. 2000). Lipídios detectados nos tecidos da galha indicam armazenagem de nutrientes que, embora não sejam diretamente utilizados pelo $E$. ostreoides, podem ser metabolizados e convertidos em componentes estruturais e metabólicos fundamentais para o desenvolvimento da galha.

A presença de amiloplastos é limitada à região vascular dos folíolos sadios (figura 25), no parênquima e na região perivascular das galhas (figura 26). A presença de amiloplastos na galha indica um dreno ativo desencadeado pelo E. ostreoides dos sítios fotossintetizantes para a galha.

Bronner (1992) observou, em condições experimentais com cecidozoa vivo, que a hipernutrição da galha, com açúcares, aumenta a síntese de amido no tecido nutritivo de reserva, devido à alta atividade da amilase no tecido nutritivo propriamente dito, e que a hiponutrição provoca quebra do amido no tecido nutritivo de reserva e aumento no acúmulo de lipídos no tecido nutritivo. Em galhas de L. muelhbergianus as reservas amilíferas e lipídicas detectadas provavelmente atuam como substâncias de reserva para manutenção metabólica da galha uma vez que o galhador tem hábito alimentar sugador.

O impacto causado pelo E. ostreoides no folíolo sadio provoca alterações químicas na planta, as quais são notadas principalmente em relação à armazenagem de substâncias de defesa. Além das substâncias nutritivas, os tecidos das galhas de L. muehlbergianus apresentaram-se ricos em derivados fenólicos e flavonoídicos, além da ampla lignificação.

Polifenóis são substâncias de extrema importância na relação parasita-hospedeiro. Estes foram detectados como conteúdos castanho claros nas células parenquimáticas, precipitados enegrecidos nas células epidérmicas e na região perivascular de folíolos sadios (figura 27). Nas galhas, houve aumento na quantidade de polifenóis caracterizado pelo acúmulo dos precipitados enegrecidos nas células epidérmicas e em todas as células parenquimáticas ao redor da câmara ninfal (figura 28). 


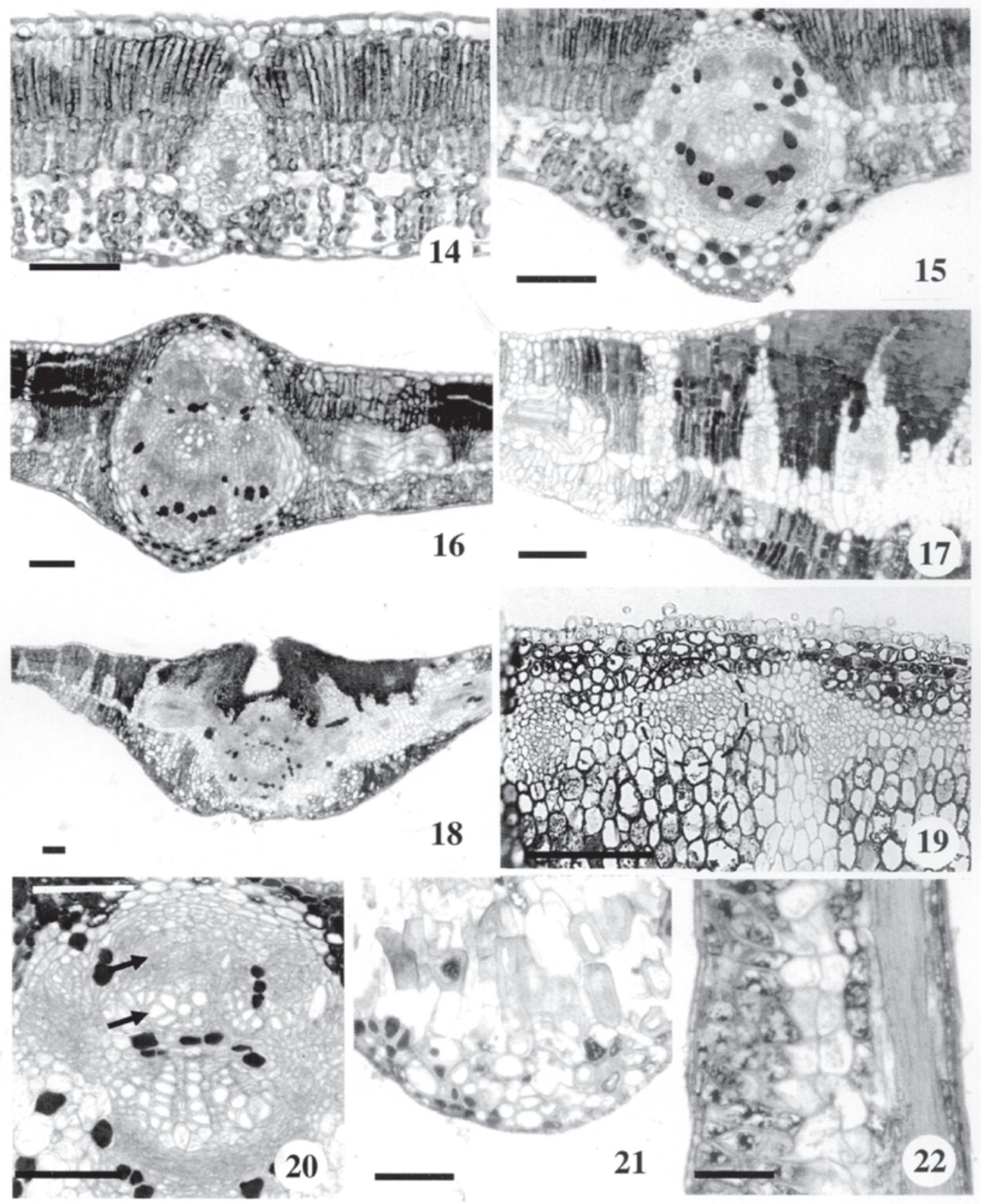

Figuras 14-22. Fotomicrografias de folíolos sadios e galhas de Lonchocarpus muehlbergianus Hassl. 14-15. Seções transversais do folíolo sadio. 14. Aspecto geral evidenciando mesofilo estratificado. 15. Detalhe de nervura de segunda ordem. 16-20. Seções transversais de galhas imaturas. 16. Fase de indução da galha, tecido vascular e parenquimático alterados. 17. Estratificação do parênquima da galha. 18. Aspecto geral de galha imatura. 19. Parede da galha em seção paradérmica ao folíolo evidenciando neoformação de tecido vascular (linhas pontilhadas). 20. Nervura de segunda ordem alterada pela ação alimentar de E. ostreoides Crawf. evidenciando hiperplasia do tecido vascular (seta). 21-22. Seção transversal da galha madura. 21. Detalhe da base da galha com intensa lignificação. 22. Detalhe da parede da galha evidenciando tecido esclerificado. Barras $=100 \mu \mathrm{m}$.

Figures 14-22. Photomicrographs of healthy leaflets and galls of Lonchocarpus muehlbergianus Hassl.. 14-15. Transverse sections of healthy leaflet. 14. General aspect showing stratified mesophyll. 15. Detail of a second order vein. 16-20. Transverse sections of immature galls. 16. Gall induction phase showing altered vascular and parenchymatic tissues. 17. Stratified gall parenchyma. 18. General aspect of immature gall. 19. Gall wall in paradermic section showing neoformation of vascular tissue (dotted lines). 20. Second order vein altered by the feeding action of $E$. ostreoides Crawf. showing vascular tissue hyperplasia (arrow). 21-22. Transverse section of mature gall. 21. Detail of the base of the gall with intense lignification. 22. Detail of gall wall showing sclerified tissue. Bars $=100 \mu \mathrm{m}$. 

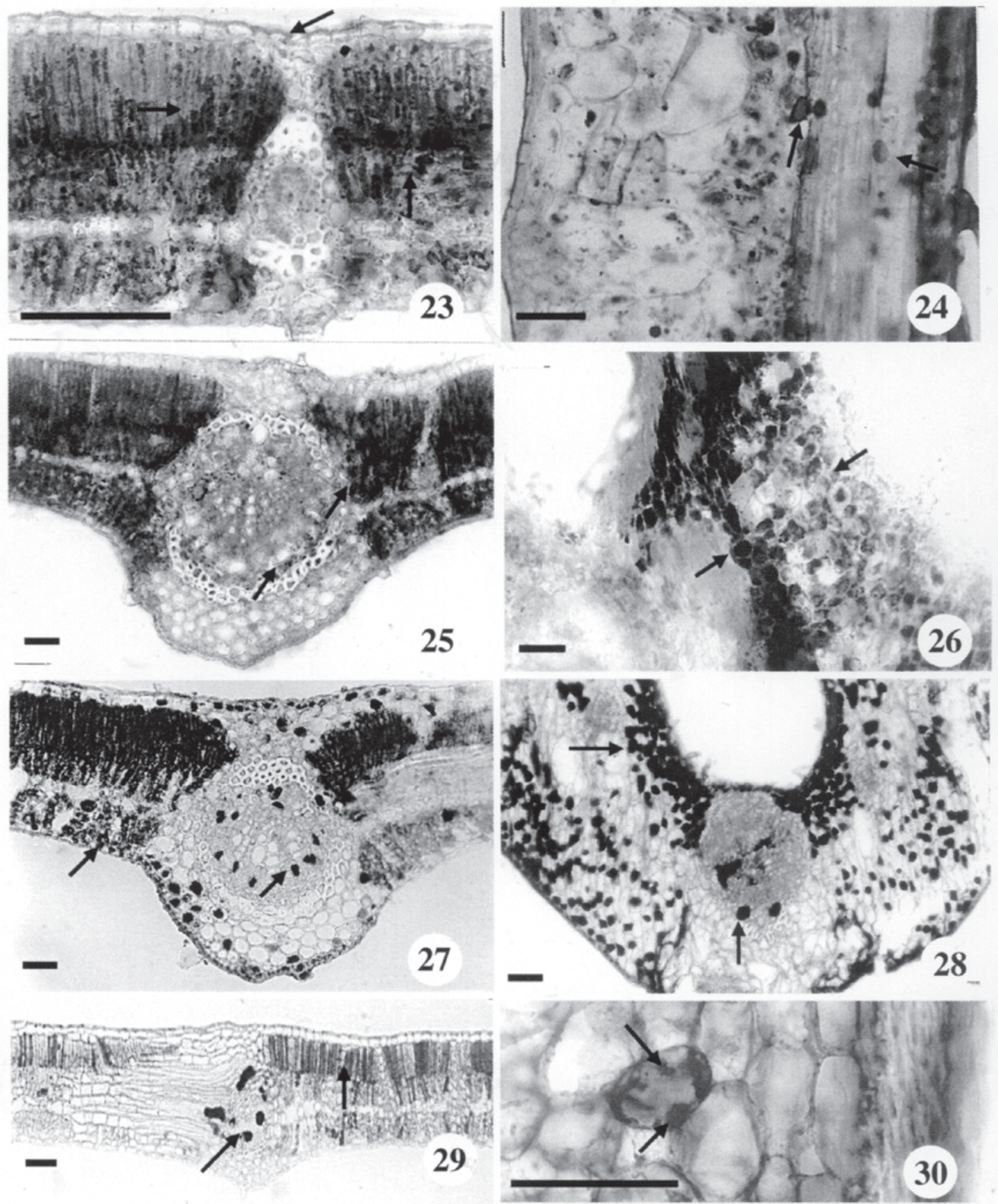

Figuras 23-30. Testes histoquímicos em seções transversais de folíolos sadios e galhas de Lonchocarpus muehlbergianus Hassl. 23. Folíolo sadio com gotículas lipídicas no mesofilo e revestimento cuticular (setas). 24. Parede da galha com gotículas lipídicas no mesofilo (setas). 25. Amiloplastos detectados no mesofilo e na região perivascular do folíolo sadio (setas). 26. Amiloplastos observados no parênquima da galha (setas). 27. Derivados fenólicos precipitados no folíolo sadio (setas). 28. Derivados fenólicos precipitados no tecido da galha madura (setas). 29. Flavonóides no folíolo sadio (setas). 30. Flavonóides detectados no tecido da galha (setas). Barras $=100 \mu \mathrm{m}(25-29), 50 \mu \mathrm{m}(23-24,30)$.

Figures 23-30. Microchemical tests in transverse sections of healthy leaflets and galls of Lonchocarpus muehlbergianus Hassl. 23. Healthy leaflet with lipidic droplets in the mesophyll and cuticle (arrows). 24. Gall wall with lipidic droplets in mesophyll (arrows). 25. Amiloplasts evidenced in the mesophyll and perivascular region of healthy leaflet (arrows). 26. Amiloplasts observed in gall parenchyma (arrows). 27. Precipitated phenolic derivatives in healthy leaflet (arrows). 28. Precipitated phenolic derivatives in mature gall tissues (arrows). 29. Flavonoids in healthy leaflet (arrows). 30. Flavonoids evidenced in gall tissue (arrows). Bars $=100 \mu \mathrm{m}(25-29), 50 \mu \mathrm{m}(23-24,30)$. 
O aumento relativo de substâncias fenólicas observado nas galhas pode representar uma resposta da planta à herbivoria. Segundo Abrahamson et al. (1991), altos níveis de fenóis em tecidos de galhas em desenvolvimento são registrados em decorrência da taxa de crescimento destes tecidos. Essa taxa de crescimento está fortemente relacionada a concentração dos hormônios, cujo balanço pode ser alterado em função da concentração de compostos fenólicos. Provavelmente, os mecanismos de ativação ou inibição do crescimento ocorreriam mediante aumento na biossíntese de fenóis, o qual inibiria as AIA-oxidases, aumentando assim a ação das auxinas, responsáveis pela hipertrofia celular (Fosket 1994) e pela conseqüente formação da galha. Os altos níveis de biossíntese de substâncias fenólicas nos tecidos das galhas são reflexo da juventude fisiológica da estrutura, na qual a atividade da PAL (fenilalaninaamonialiase) é alta (Hartley 1998), além de poderem atuar como uma barreira que protege o inseto indutor do ataque de outros herbívoros (Cornell 1983, Hartley 1998).

Assim como na galha, os tecidos foliares sadios apresentaram reação positiva para flavonóides por todo o parênquima (figuras 29, 30). Contudo, compostos flavonoídicos formaram sais de oxônio com ácido sulfúrico aquoso concentrado exclusivamente no parênquima ao redor da câmara ninfal de galhas em diferentes estágios de desenvolvimento. A formação destes cristais somente nos tecidos das galhas indicam resposta específica ao estresse biótico induzido pelo endofitófago. O composto flavônico precursor dos cristais de oxônio pode funcionar como um sinalizador, evitando a oviposição de coespecíficos no sítio de formação inicial das galhas. Por outro lado, pode atrair predadores e parasitóides para este mesmo sítio. $\mathrm{O}$ envolvimento dos flavonóides em diversas interações inseto-planta, e sua ação como sinalizadores químicos na polinização, dispersão dos frutos e sementes, e na herbivoria já foram anteriormente referidos por Rosenthal \& Berenbaun (1991).

Flavonas, flavonóis e flavanonas foram observados nos tecidos foliares sadios, nas camadas periféricas das galhas e ao redor da loja (tabela 2). Muito embora a presença e a função dos derivados fenólicos nos tecidos das galhas tenha sido estudada por muitos autores (Cornell 1983, Taper \& Case 1987, Schultz 1992, Hartley 1998), o papel dos flavonóides na sinalização entre insetos indutores de galhas e a suscetibilidade das espécies hospedeiras é praticamente desconhecida.

A presença de flavonóides, nos folíolos sadios e nas galhas de L. muehlbergianus, pode estar relacionada à capacidade de E. ostreoides detectar sinalizadores químicos importantes nos processos de localização, escolha e aceitação da planta hospedeira, como apontado por Araújo (1997) e Gottlieb et al. (1996). Flavonas e flavonóis, conhecidos como eficientes protetores contra radiação UV (Price 1977), foram observados nos tecidos foliares sadios, nas camadas periféricas das galhas e ao redor da câmara larval. Flavanonas foram detectadas nas células parenquimáticas dos folíolos sadios e no córtex das galhas. Tal classe de flavonóides pode apresentar sabor amargo (Zuanazzi 2000) podendo deste modo, proteger o parasita do ataque de cecidófagos.

L. muehlbergianus está submetida a um alto estresse induzido pela ação do E. ostreoides o qual promove alterações estruturais nos sistemas de revestimento, fundamental e vascular, conferindo ao galhador proteção e nutrição. A caracterização dessas alterações constitui um passo importante para o estabelecimento de um modelo morfogênico de galhas de Psyllidae, a semelhança dos propostos por Bronner (1992) para galhas de Cecidomyiidae e Cynipidae. A avaliação da ocorrência de derivados flavonoídicos em tecidos de galhas, especialmente a formação de cristais de oxônio exclusivamente nos tecidos galhados, é inédito para os sistemas galhador-planta. O acúmulo de reservas em um tecido nutritivo é também um fato novo para galhas de Psyllidae, os quais são típicos sugadores de floema. Esse acúmulo de substâncias que podem ser utilizadas no desenvolvimento e manutenção das galhas é oriundo das alterações no metabolismo primário da planta hospedeira, enquanto que aquelas relativas ao metabolismo secundário sugerem defesas da planta

Tabela 2. Reações para compostos flavonoídicos nos tecidos foliolares sadios e nas galhas de Lonchocarpus muehlbergianus Hassl. induzidas por Euphalerus ostreoides Crawf. (+ = reação positiva; - = reação negativa).

Table 2. Reactions to flavonoidic compounds in the tissues of healthy leaflets and galls of Lonchocarpus muehlbergianus Hassl. induced by Euphalerus ostreoides Crawf. (+= positive reactions; - = negative reaction).

\begin{tabular}{lccc}
\hline Compostos flavonoídicos & $\begin{array}{c}\text { Folíolo } \\
\text { sadio }\end{array}$ & $\begin{array}{c}\text { Galha } \\
\text { imatura }\end{array}$ & $\begin{array}{c}\text { Galha } \\
\text { madura }\end{array}$ \\
\hline Flavonas & + & + & + \\
Flavonóis & + & + & + \\
Flavanonas & + & + & + \\
Cristais de oxônio & - & + & + \\
\hline
\end{tabular}


contra herbivoria. As mudanças estruturais e químicas observadas são reações de defesa da planta e mecanismos de adaptação que favorecem o estabelecimento do galhador nos tecidos vegetais.

Agradecimentos - Ao CNPq, pela bolsa de iniciação científica; à Dra. Jane Elizabeth Kraus, pelo auxílio nas análises em Microscopia Eletrônica de Varredura realizadas no Laboratório de Microscopia Eletrônica do Instituto de Biociências da Universidade de São Paulo; à Bióloga Ana Silvia Franco Pinheiro Moreira, pela leitura crítica do texto.

\section{Referências bibliográficas}

ABRAHAMSON, W.G., MCCREA, K.D., WHITWELL, A.J. \& VERNIERI, L.A. 1991. The role of phenolics in goldenrod ball gall resistance and formation. Biochemical Systematics and Ecology 19:615-622.

ARAÚJO, M.C.P. 1997. Aspectos ecológicos e evolutivos da interação entre animais e plantas. In Interações ecológicas e biodiversidade (M.C.P. Araújo, G.C. Coelho \& I. Medeiros, eds.). Unijui, Ijuí, p.11-48.

BRONNER, R. 1975. Simultaneous demonstration of lipids and starch in plant tissues. Stain Technology 50:1-4.

BRONNER, R. 1992. The role of nutritive cells in nutrition of cynipds and cecidomyiids. In Biology of insect-induced galls (J.D. Shorthouse \& O. Rohfristsch, eds.). Oxford University Press, New York, p.118-140.

BRUNDETT, M.C., KENDRICK, B. \& PETERSON, C.A. 1991. Efficient lipid staining in plant material with Sudan Red 7B or fluoral yellow 088 in polyethylene glycol-glycerol. Biotechnic \& Histochemistry 66:111-116.

BUCHANAN, B.B., GRUISSEM, W. \& JONES, R.L. 2000. Biochemistry and molecular biology of plants. American Society of Plant Physiologist, Rockville.

BUKATSCH, F. 1972. Bermerkungen zur Doppelfärbung Astrablau-Safranin. Mikrokosmos 61:255.

CASTrO, H.G., FERREIRA, F.A., SILVA, D.J.H. \& MOSQUIM, P.R. 2004. Contribuição ao estudo das plantas medicinais metabólitos secundários. Ed. dos autores, Viçosa.

CORNELL, H.V. 1983. The secondary chemistry and complex morphology of galls formed by the cynipinae (Hymenoptera): why and how? American Midland Naturalist 110:225-234.

FAHN, A. 1990. Plant anatomy. Pergamon Press, Oxford.

FELTON, G.W. \& EICHENSEER, H. 1999. Herbivore saliva and its effects on plant defense against herbivores and pathogen. In Induced plant defenses against pathogens and herbivores: biochemistry, ecology, and agriculture (A.A. Agrawal, S. Tuzun, \& E. Bent, eds.). American Phytopathological Society Press, Saint Paul, p.19-36.
FERREIRA, S.A., FERNANDES G.W. \& CARVALHO, L.G. 1990. Biologia e história natural de Euphalerus ostreoides (Homoptera: Psyllidae) cecidógeno de Lonchocarpus guilleminianus (Leguminosae). Revista Brasileira de Biologia 50:417-423.

FEUCHT, W., SCHMID, P.P.S. \& MARTINS, R.P. 1986. Distribution of flavonols in meristematic and mature tissues of Prunnus avium shoots. Journal of Plant Physiology 125:1-8.

FOSKET, D.E. 1994. Plant growth and development. Academic Press. San Diego.

GLOVER, B.J. 2000. Differentiation in plant epidermal cells. Journal of Experimental Botany 51:497-505.

GOTTLIEB, O.R., KAPLAN, M.A.C. \& BORIN, M.R.M.B. 1996. Biodiversidade: Um enfoque químico-biológico do funcionamento da natureza. Universidade Federal do Rio de Janeiro, Rio de Janeiro.

GUTSCHICK, V.P. 1999. Research reviews: biotic and abiotic consequences of differences in leaf structure. New Phytology 143:3-18.

HARKIN, J.M. \& OBST, J.R. 1973. Lignification in trees: indication of exclusive peroxidase participation. Science 180:266-198.

HARTLEY, S.E. 1998. The chemical composition of plant galls: are levels of nutrients and secondary compounds controlled by the gall former? Oecologia 113:492-501.

HARTLEY, S.E. 1999. Are gall insects large rhizobia? Oikos 84:333-342.

HORI, K. 1992. Insect secretion and their effect on plant growth, with special reference to hemipterans. In Biology of insect-induced galls (J.D. Shorthouse \& O. Rohfritsch, eds.). Oxford University Press, New York, p.157-170.

ISAIAS, R.M.S. 1998. Galhas entomógenas em Machaerium (Leguminosae-Papilionoidae): anatomia e histoquímica. Tese de doutorado. Universidade de São Paulo, São Paulo.

JOHANSEN, D.A. 1940. Plant microtechnique. McGraw-Hill Book, New York.

KRAUS, J.E. 1997. Respostas morfogenéticas de plantas a indutores galhadores. In Interações ecológicas e biodiversidade (M.C.P. Araújo, G.C. Coelho \& I. Medeiros, eds.). Unijui, Ijuí, p.59-76.

KRAUS, J.E. \& ARDUIN, M. 1997. Manual básico de métodos em morfologia vegetal. Editora da Universidade Federal Rural do Rio de Janeiro, Seropédica.

KRAUS, J.E., SUGIURA, H.C. \& CUTRUPI, S. 1996. Morfologia e ontogenia em galhas entomógenas de Guarea macrophylla subsp. tuberculata. Fitopatologia Brasileira 21:349-356.

LANGE, B.M., LAPIERRE, C. \& SANDERMANN, H. JR. 1995. Elicitor-induced spruce stress lignin. Plant Physiology 108:1277-1287.

LOW, P.S. \& MERIDA, J.R. 1996. The oxidative burst in plant defense: function and signal transduction. Plant Physiology 96:533-542. 
MANI, M.S. 1964. Ecology of plant galls. Dr. W. Junk Publishers, The Hague.

MEYER, J. \& MARESQUELLE, H.J. 1983. Anatomie des galles. Gebrüder Borntraeger, Berlin.

MOORE, A.E.P., ASHFORD, A.E. \& PETERSON, R.L. 1991. Reserve substances in Paxillus involutus sclerotia. Determination by histochemistry and X-ray microanalysis. Protoplasma 163:67-81.

O'BRIEN, T.P. \& MCCULLY, M.E. 1981. The study of plant structure principles and selected methods. Termarcarphi Pty, Melbourne.

PRESS, M.C. 1999. The functional significance of leaf structure: a search for generalizations. New Phytology 143:213-30.

PRICE, P.W. 1997. General concepts on the evolutionary biology of parasites. Evolution 31:405-420.

QUEIROZ, C.G.S., ALONSO, A., MARES-GUIA, M. \& MAGALHÃES, A.C. 1998. Chilling-induced changes in membrane fluidity antioxidant enzyme actives in Coffea arabica L. roots. Biological Plantarum 41:403-413.

RAO, M.V., PALIYATH, G. \& ORMROD, D.P. 1996. Ultraviolet-B and ozone-induced biochemical changes in antioxidant enzymes of Arabidopsis thaliana. Plant Cell 8:1809-1819.

ROHFRITSCH, O. \& SHORTHOUSE, D. 1982. Insect galls. In Molecular biology of plant tumors (G. Kahl \& J.S. Shell, eds.). Academic Press, New York.

ROSENTHAL, G.A. \& BERENBAUN, M.R. 1991. Herbivores: their interactions with secondary plant metabolites: ecological and evolutionary processes. $2^{\text {nd }}$ ed. v.1, Academic Press, New York.
SCHULTZ, B.B. 1992. Insect herbivores as potential causes of mortality and adaptation in gall-forming insects. Oecologia 90:297-299.

SOARES, G.L.G., ISAIAS, R.M.S., GONÇALVES, S.J.M.R. \& CHRISTIANO, J.C.S. 2000. Alterações químicas induzidas por coccídeos galhadores (Coccoidea: Brachyscelidae) em folhas de Rollinia laurifolia Schdtl. (Annonaceae). Revista Brasileira de Zoociências 2:103-116.

SOUZA, S.C.P.M., KRAUS, J.E., ISAIAS, R.M.S. \& NEVES, L.J. 2000. Anatomical and ultrastructural aspects of leaf galls in Ficus microcarpa L.F. (Moraceae) induced by Gynaikothrips ficorum Marchal (Thysanoptera). Acta Botanica Brasilica 14:57-69.

STONE, G.A. 2003. The adaptive significance of insect gall morphology. Trends in Ecology and Evolution 18:512-522.

TAPER, M.L. \& CASE, T.J. 1987. Interactions between oak tannins, and parasite community structure: unexpected benefits of tannins to cynipid gall-wasps. Oecologia 71:254-261.

TEIXEIRA, S.P., CASTRO, M.M. \& TOZZI, M.G.A. 2000. Secretory cavities and pellucid dots in leaflets of Lonchocarpus (Leguminosae, Papilionoideae, Millettieae). Plant Systematics and Evolution 221:61-68.

WOODMAN, R.L. \& FERNANDES, G.W. 1991. Differential mechanical defense: herbivory, evapotranspiration, and leaf-hairs. Oikos 60:11-19.

ZUANAZZI, J.A.S. 2000. Flavonóides. In Farmacognosia: da planta ao medicamento (C.M.O. Simões, E.P. Schenkel, G. Gosmann, J.C.P. Mello, L.A. Mentz \& P.R. Petrovik, eds.). $2^{\mathrm{a}}$ ed. Editora da UFSC, Santa Catarina, p.489-516. 